Journal of Advanced Research in Fluid Mechanics and Thermal Sciences

Journal homepage: www.akademiabaru.com/arfmts.html ISSN: 2289-7879

\title{
Optimization of The Through-The-Road Parallel Hydraulic Hybrid Drive Train
}

Muhammad Iftishah Ramdan ${ }^{1, *}$, Khairul Anuar Idris ${ }^{1}$, Yeoh Ying Heng ${ }^{1}$, Muhammad Syahir Mahyuddin $^{1}$, Mohd Azmi Ismail ${ }^{1}$, Ahmad Faizul Hawary ${ }^{1}$

School of Mechanical Engineering, Universiti Sains Malaysia, Nibong Tebal, Penang, Malaysia

\section{ARTICLE INFO}

\section{Article history:}

Received 13 May 2020

Received in revised form 7 August 2020

Accepted 10 August 2020

Available online 3 September 2020

\section{Keywords:}

Hydraulic hybrid; Energy consumption;

Affordability; Retrofitting; Attainability

\section{ABSTRACT}

The through-the-road (TTR) hydraulic hybrid parallel architecture uses regenerative braking system that is placed at the rear wheels. This architecture offers a practical solution for an efficient passenger vehicle because it does not interfere with the conventional drive train. Thus, unlike other hybrid vehicles, this architecture allows the use of hybrid technology on an existing front-wheel-drive vehicle. This paper discusses the development of the architecture that involves the hydraulic circuit design and the optimization of the components size. The study simulates 972 vehicle models on all four segments on Worldwide Harmonized Light Vehicle Test Procedure (WLTP) drive cycle. The simulation finds the suitable model uses a $25 \mathrm{cc} / \mathrm{rev}$ hydraulic pump, a 50 $\mathrm{cc} / \mathrm{rev}$ hydraulic motor and a 10-liter hydraulic accumulator. The chosen combination allows the pump and the motor to operate within their limits, and maximizes the use of regenerative braking throughout the full WLTP drive cycle.

Copyright $@ 2020$ PENERBIT AKADEMIA BARU - All rights reserved

\section{Introduction}

The development of efficient passenger vehicles has become one of the popular research areas due to concerns about excessive fossil fuel consumption and the impact of carbon emissions to the environment [1]. Hybrid drive train has been proven to reduce the energy consumption and the carbon emissions [12] through regenerative braking but it is not widely used in developing countries. This can be seen by the sales of Toyota Prius hybrid electric vehicle (HEV) has been excellent in the developed country like in the United States of America since the early year 2000 [2]. Yet, the sales of $\mathrm{HEV}$ has been very poor in the developing countries. This is due to the low purchasing power of lowincome consumers limiting their ability to purchase and maintain HEVs.

The through-the-road hydraulic hybrid parallel architecture could be the answer of the low attainability rate of efficient hybrid vehicles since the architecture allows for the retrofitting of the

\footnotetext{
${ }^{*}$ Corresponding author.

E-mail address: shahramdan@usm.my
} 
regenerative braking components into an existing conventional vehicle. The hydraulic system is very robust and can be maintained by any mechanics because of its simplicity [3]. This way, low-income consumers do not have to commit to buy a brand-new vehicle and they can maintain it like any other conventional vehicles.

A hybrid vehicle uses a regenerative braking system to recover the kinetic energy during braking, which can be reused later to propel the vehicle [16]. A hybrid hydraulic Vehicle (HHV) offers high power-density components for the high frequency regenerative braking, allowing the vehicle to recover large amounts of energy in a short period of time [4,11]. During braking, the vehicle momentum drives the hydraulic pump to charge the hydraulic accumulator, where the kinetic energy is stored as potential energy in the form of high-pressure fluid. During acceleration, the stored energy is used by releasing the high-pressure fluid in the accumulator to drive a hydraulic motor.

HHV architectures can be classified into parallel, series, and power split $[8,13]$. The parallel architecture is the simplest of all three because it is similar to that of the conventional drive train, but is equipped with additional hydraulic hybrid components that allow regenerative braking. The through-the-road parallel architecture presented in this paper further simplifies the parallel architecture because it does not interfere with the front wheel drive conventional drive train [10].

This paper optimizes the through-the-road parallel HHV components installed in a Perodua Myvi passenger vehicle. The optimization process involves the simulation of vehicle mathematical model with rule-based control strategy similar to the ones found in previous study [5]. The optimization runs the simulation for 972 times for one drive cycle to obtain the optimal combination of components.

\section{Methodology}

The through-the-road parallel HHV architecture places a regenerative braking system at the rear wheels and does not interfere with the conventional drive train. This allows the retrofitting of the hybrid system into a front-wheel-drive conventional vehicle, like a Perodua Myvi. The hydraulic hybrid system consists of a hydraulic pump, a clutch, an accumulator, a check valve, a pressure relief valve, a 3/2-way valve and a hydraulic motor (Figure 1).

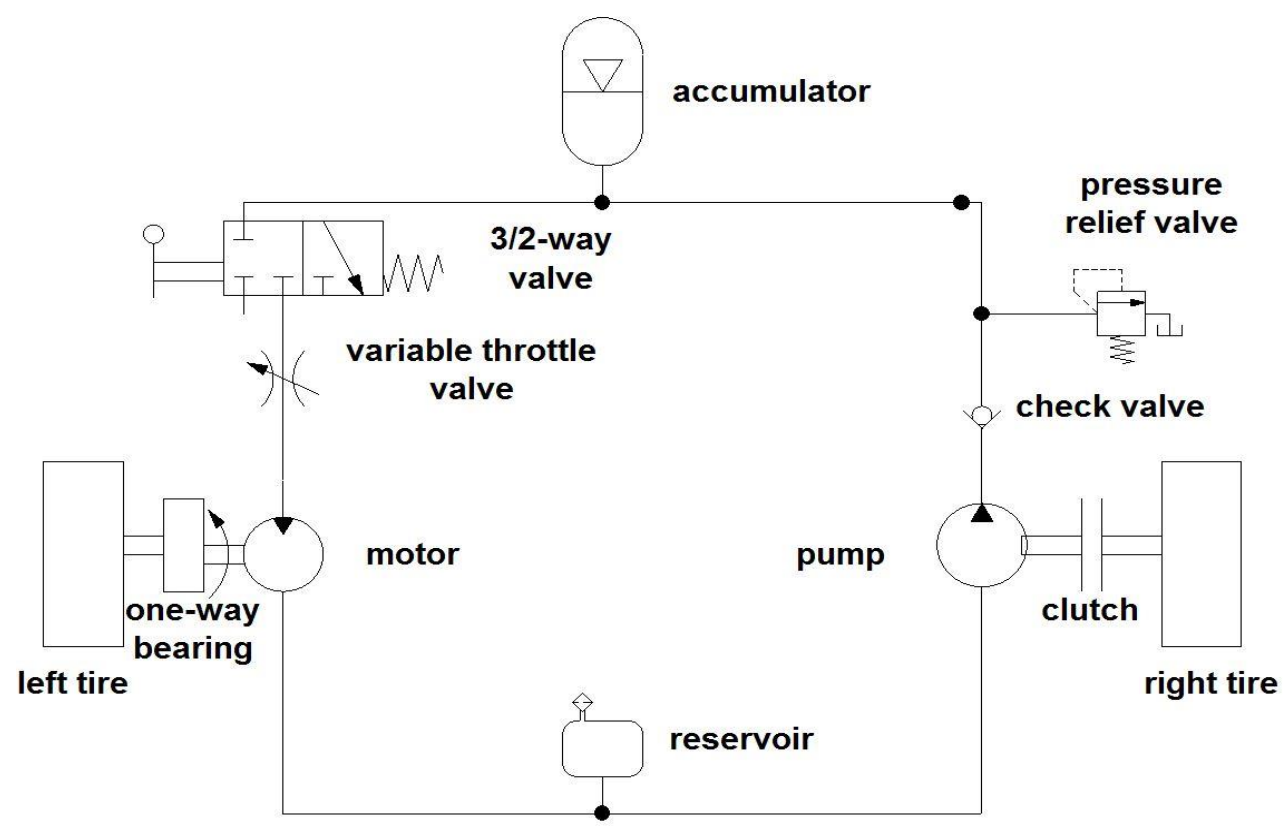

Fig. 1. Through-The-Road Parallel Hydraulic Hybrid Drive Train Hydraulic Circuit 
During braking, the right wheel clutch is engaged to the hydraulic pump that charges the accumulator. A pressure relief valve is used to ensure the accumulator pressure does not exceed the maximum operating pressure of any of the components (14 $\mathrm{MPa}$ ). A check valve is used to ensure the high-pressure fluid does not flow back to the pump.

During acceleration, the 3/2-way valve is valve is moved, to release the high-pressure fluid from the accumulator and to drive the hydraulic motor at the left wheel. Simultaneously, the proportional valve is used, to control the motor's speed and torque.

The sizes of the components involved in the regenerative braking process need to be optimized according to the vehicle's demands. In this study, the HHV component optimization is done by simulating the vehicle's mathematical model with all the combinations of component sizes on various drive cycles to estimate their fuel economy. The component candidates are shown as follows.

\subsection{Hydraulic Pump}

The hydraulic pump is located at the right wheel, and is connected to a clutch, so that it can be disengaged when braking is not needed. There are three generic hydraulic gear pump candidates (Table 1). When the clutch is engaged, the pump is connected the right wheel via a gear box so that the pump is able to operate within its speed range. The gear ratio for GB1 is the ratio of the pump speed to the wheel speed (Eq. (1)). This is also included in the sizing simulation, with six possible candidates, which are: $4,4.2,4.4,4.6,4.8$ and 5.

Table 1

Gear pumps candidates

\begin{tabular}{lllll}
\hline $\begin{array}{l}\text { Pump displacement, Dp } \\
\text { (cc/rev) }\end{array}$ & Mass (kg) & Min. speed (RPM) & $\begin{array}{l}\text { Max. speed } \\
\text { (RPM) }\end{array}$ & $\begin{array}{l}\text { Max pressure } \\
(\mathrm{MPa})\end{array}$ \\
\hline 16.5 & 3.05 & 500 & 3000 & 25.0 \\
19.2 & 3.2 & 500 & 3000 & 25.0 \\
25 & 3.5 & 500 & 3000 & 25.0 \\
\hline
\end{tabular}

The hydraulic pump provides the high-pressure fluid flow, which its rate depends on the speed and the displacement (Eq. (2)). A volumetric efficiency $\left(\eta_{v o l}\right.$. ) of $60 \%$ is included, to represent the internal leakage of the pump [14]. The pumping torque $\left(T_{p}\right)$ that would stop the vehicle depends on the HPA pressure $\left(P_{H P A}\right)$ (Eq. (3)). A mechanical efficiency $\left(\eta_{\text {mech. }}\right)$ of $98 \%$ is also included to represent the friction loss in the pump.

$\omega_{p}=\omega_{w} G R 1$

$Q_{p}=\eta_{v o l .} D_{p} \omega_{p}$

$T_{p}=\frac{D_{p} P_{H P A}}{\eta_{\text {mech }}}$

where

$\omega_{p}=$ Pump rotational speed $\left(\mathrm{rads}^{-1}\right)$

$\omega_{w}=$ Wheel rotational speed $\left(\mathrm{rads}^{-1}\right)$

$G R 1=$ Gear ratio of $G B 1$

$Q_{p}=$ Flow rate across pump $\left(m^{3} s^{-1}\right)$ 


\subsection{Hydraulic Motor}

The hydraulic motor is located at the left wheel, and is connected to a one-way bearing, so that it can be disengaged when the wheel speed exceeds its maximum speed. Three readily available orbital geroler hydraulic motors are tested in the simulation (Table 2). The motor is connected to gear box 2 (GB2), so that the motor can optimally deliver the torque during acceleration. The GB2 gear ratio is the ratio of the motor speed to the wheel speed I (Eq. (4)). GB2 is included in the size optimization simulation with six candidates: $0.4,0.6,0.8,1,1.2$, and 1.4.

Table 2

Orbital geroler motors candidates

\begin{tabular}{llllll}
\hline $\begin{array}{l}\text { Motor displacement, Dm } \\
\text { (cc/rev) }\end{array}$ & Mass (kg) & $\begin{array}{l}\text { Min speed } \\
\text { (RPM) }\end{array}$ & $\begin{array}{l}\text { Max speed } \\
(\mathrm{RPM})\end{array}$ & $\begin{array}{l}\text { Max torque } \\
(\mathrm{Nm})\end{array}$ & $\begin{array}{l}\text { Max pressure } \\
(\mathrm{MPa})\end{array}$ \\
\hline 50 & 12 & 0 & 755 & 100 & 14.0 \\
63 & 12 & 0 & 750 & 124 & 14.0 \\
80 & 12 & 0 & 630 & 190 & 17.5 \\
\hline
\end{tabular}

The hydraulic motor provides torque $\left(T_{m}\right)$, which depends on the HPA pressure $\left(P_{H P A}\right)$ and the displacement $\left(D_{m}\right)$ (Eq. (5)). The motor also requires fluid flow which its rate depends on its speed and displacement $\left(D_{m}\right)$ (Eq. (6)). Like the pump, a mechanical efficiency $\left(\eta_{\text {mech. }}\right.$ ) of $98 \%$ and a volumetric efficiency $\left(\eta_{v o l}.\right)$ of $60 \%$ are included to represent the friction loss and internal leakage, respectively.

$\omega_{m}=\omega_{w} G R 2$

$T_{m}=\eta_{\text {mech. }} D_{m} P_{H P A}$

$Q_{m}=\frac{D_{m} \omega_{m}}{\eta_{v o l}}$

where

$\omega_{m}=$ Motor rotational speed $\left(\mathrm{rads}^{-1}\right)$

$G R 2=$ Gear ratio of $G B 2$

$Q_{m}=$ Flow rate across motor $\left(m^{3} s^{-1}\right)$

\subsection{Hydro-Pneumatic High-Pressure Accumulator (HPA)}

A bladder type hydro-pneumatic accumulator is used to store the potential energy in the form of a high-pressure hydraulic fluid. The high-pressure accumulator (HPA) is set to operate at pressures between $7 \mathrm{MPa}$ and $14 \mathrm{MPa}$. Three HPA candidates are simulated, to determine the optimal HPA size for the HHV (Table 3).

\section{Table 3}

High Pressure Accumulator size candidates

\begin{tabular}{llll}
\hline HPA sizes $(\mathrm{L})$ & Mass $(\mathrm{kg})$ & Min pressure $(\mathrm{MPa})$ & Max pressure $(\mathrm{MPa})$ \\
\hline 10 & 40 & 7 & 14 \\
20 & 63 & 7 & 14 \\
35 & 102 & 7 & 14 \\
\hline
\end{tabular}


The HPA pressure can be calculated by first calculating the total volumetric flow rate $\left(Q_{t}\right)$, or the rate of change in the fluid volume inside the HPA, at every time step (Eq. (7)). Since the hydropneumatic accumulator compresses the nitrogen gas by using a hydraulic fluid, the rate of change in the gas volume $\left(\Delta V_{g}\right)$ is equal to the negative of the rate of change in the fluid volume $\left(\Delta V_{f}\right)$ as shown in Eq. (8).

Using iteration-discretization method in Eq. (9), the current HPA gas volume $\left(V_{g}(t)\right)$ is calculated by adding the rate of change in the gas volume $\left(\Delta V_{g}\right)$ and the previous gas volume $\left(V_{g}(t-1)\right)$. Next, the Ideal Gas Law for adiabatic process is used to determine the HPA pressure (Eq. (10)) and from there, the state of charge (SOC) of the HPA can be calculated (Eq. (11)).

$$
\begin{aligned}
& Q_{t}=\frac{\Delta V_{f}}{\Delta t}=Q_{p}-Q_{m} \\
& \frac{\Delta V_{g}}{\Delta t}=-\frac{\Delta V_{f}}{\Delta t}=-Q_{t} \\
& V_{g}(t)=V_{g}(t-1)+\frac{\Delta V_{g}}{\Delta t}=V_{g}(t-1)-Q_{t} \Delta t \\
& P_{H P A}(t)=P_{H P A, o}\left(\frac{V_{g, 0}}{V_{g}(t)}\right)^{\gamma} \\
& S O C=\frac{P_{H P A}(t)-P_{\min }}{P_{\max }-P_{\min }}
\end{aligned}
$$

where

$\Delta t=$ time step $(s)$

$V_{g, 0}=$ Initial accumulator gas volume $\left(\mathrm{m}^{3}\right)$

$\gamma=$ Heat capacity ratio of nitrogen gas in accumulator

$P_{\text {min }}=$ Minimum gas pressure of accumulator $(\mathrm{Pa})$

$P_{\text {max }}=$ Maximum gas pressure of accumulator $(P a)$

\subsection{Optimization Simulation}

There are 972 combinations of components, consisting of three pumps, three motors, six GR1, six GR2, and three accumulator candidates. The coding utilizes nested loops to build vehicle mathematical models for all 972 combinations. Each model is simulated on a class-3 vehicle WLTP drive cycle (Figure 2), to estimate their fuel economy values. A class-3b vehicle refers to a vehicle

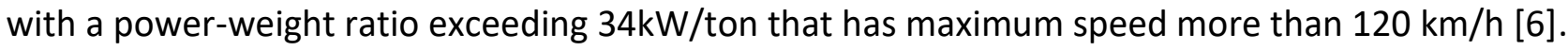

The WLTP drive cycle consists of four segments, and each segment yields a different optimal HHV combination. The low region of a class-3 WLTP drive cycle represents the slow, stop-and-go traffic in a typical city. The medium region represents driving conditions in suburban areas, where vehicles can move faster, due to the roads being less congested. High and extra high regions represent high-speed highway traffic. The simulation is run, to find the best combinations of components on city, suburban, highway, and the entire class-3 WLTP drive cycles. 


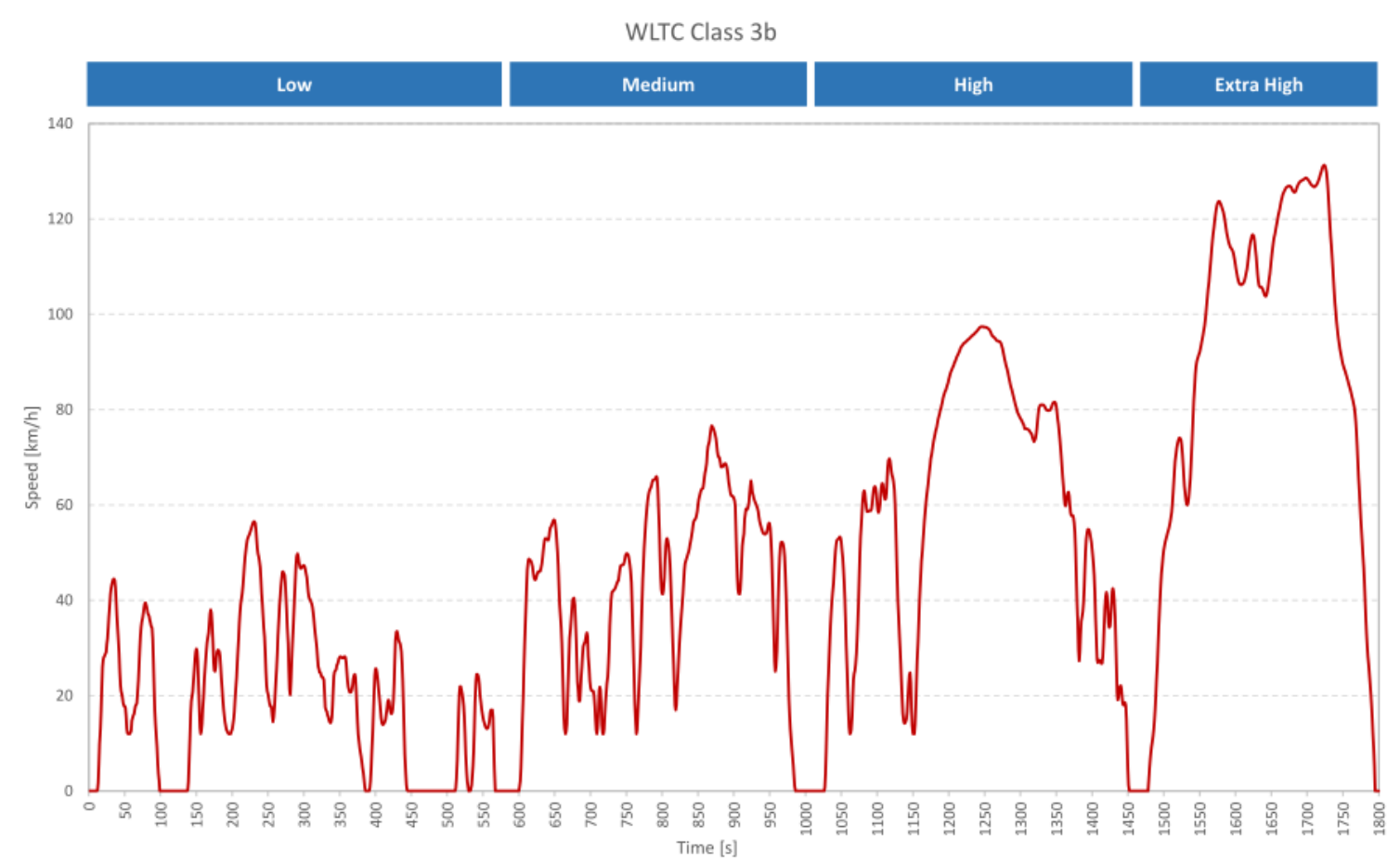

Fig. 2. WLTP for Class-3 Vehicle Drive Cycle [6]

Using the drive cycle as input, the simulation algorithm discretizes the speed into an array of onesecond time steps. At every time step, the average speed and acceleration of the vehicle from the drive cycle are fed into the vehicle model to calculate the acceleration, the tractive force, and the torque needed at the wheels [15]. From the wheel demand calculated, the load torque and the speed of the engine are determined by the rule-based control strategy [5]. The fuel consumption of the engine at the specific time step is then estimated using the fuel consumption engine map [3]. The simulation later calculates the fuel economy of the vehicle model running on a drive cycle segment. From the simulations of all 972 combinations of vehicle models, the combination with the highest fuel economy for most of the drive cycle segments is chosen to be our optimal-through-the-road parallel hybrid system.

\section{Results}

The larger the hydraulic components, the lower the fuel consumption, due to the regenerative braking. However, larger components would make the vehicle heavy, negatively affecting the fuel economy. Thus, the optimal fuel economy requires a balance between weight and component size. The 972 possible HHV combinations are simulated on four WLTP segments to find their fuel economy values. The HHV model that yields the highest fuel economy is the optimal component combination for that specific segment in the WLTP drive cycle (Table 4).

\section{Table 4}

Suitable vehicle model for segments of WLTP drive cycle

\begin{tabular}{lllllll}
\hline Drive cycle & $\begin{array}{l}\text { Pump size } \\
\text { (cc/rev) }\end{array}$ & $\begin{array}{l}\text { Pump gear } \\
\text { ratio }\end{array}$ & $\begin{array}{l}\text { Motor size } \\
\text { (cc/rev) }\end{array}$ & $\begin{array}{l}\text { Motor gear } \\
\text { ratio }\end{array}$ & HPA size (L) & $\begin{array}{l}\text { Fuel economy } \\
\text { (MPG) }\end{array}$ \\
\hline WLTP low & 25 & 2.8 & 50 & 1 & 10 & 48.30 \\
WLTP medium & 25 & 2.8 & 50 & 1.8 & 10 & 47.07 \\
WLTP high & 25 & 2.8 & 50 & 1 & 10 & 45.08 \\
WLTP extra high & 25 & 2.8 & 50 & 1 & 10 & 35.26 \\
Full WLTP & 25 & 2.8 & 50 & 1 & 10 & 41.41 \\
\hline
\end{tabular}


The results show the most suitable hydraulic pump is $25 \mathrm{cc} / \mathrm{rev}$, the optimal hydraulic motor is 50 $\mathrm{cc} / \mathrm{rev}$ and the best HPA is $10 \mathrm{~L}$ for all WLTP drive cycle segments. The optimal pump gear ratio is 2.8 for all segments. For the hydraulic motor, however, the optimal gear ratio is 1 for all segments except for the medium WLTP segment, where the optimal gear ratio is 1.8. Thus, the chosen components are the $25 \mathrm{cc} / \mathrm{rev}$ pump with the gear ratio of 2.8 , the $50 \mathrm{cc} / \mathrm{rev}$ motor with the gear ratio of 1.0 , and the 10L HPA.

As the simulation of the optimal HHV on the full WLTP drive cycle shows, regenerative braking helps with vehicle braking and acceleration, especially during the city drive cycle (Figure 3), as evidenced by the SOC profile increasing during low-speed decelerations and decreasing during lowspeed accelerations. The highway segment of the drive cycle, on the other hand, does not allow the use of regenerative braking as evidenced by the SOC profile that stays flat most of the time step of the highway segment. This is because the hybrid system cannot work at high speeds, due to pump and motor physical limitations.
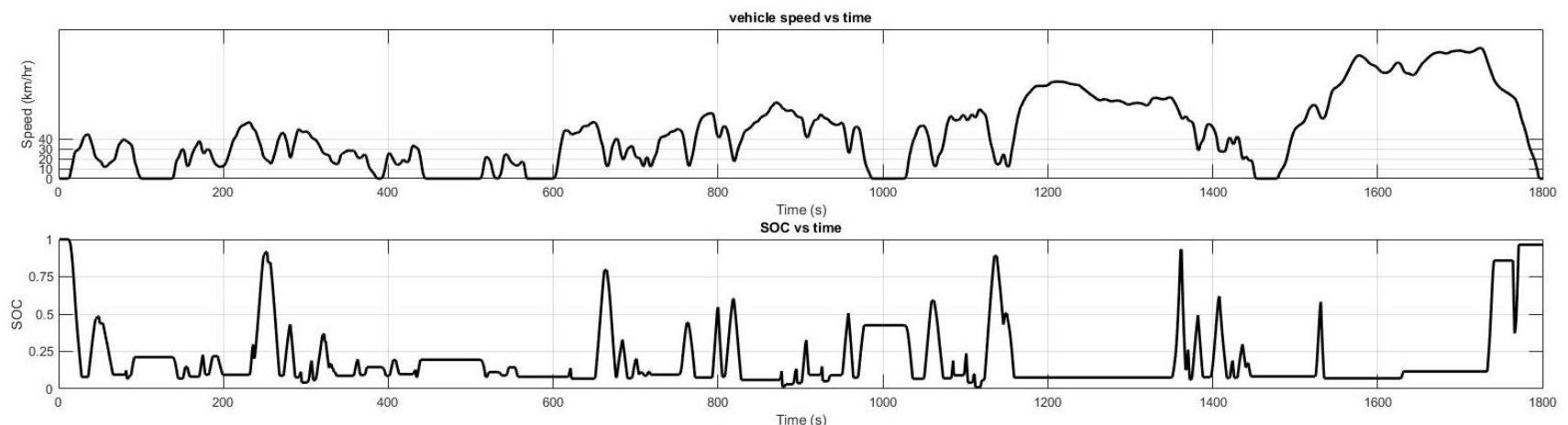
Time (s)
engine operating torque vs time

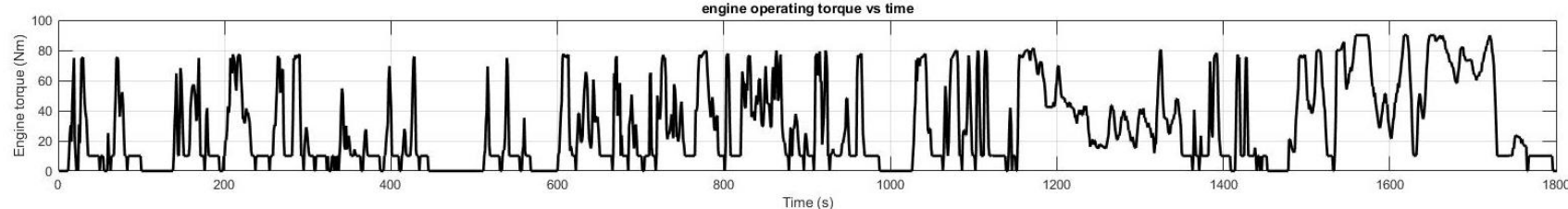
engine speed vs time

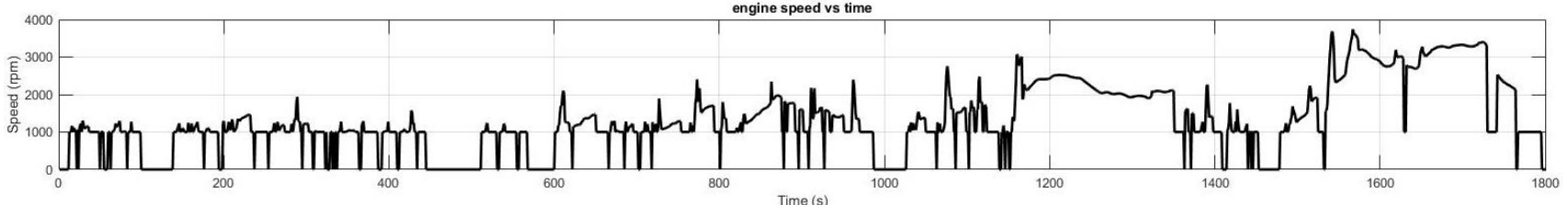

Fig. 3. Simulation Results from Full WLTP Drive Cycle

\section{Conclusions}

The through-the-road parallel hydraulic hybrid architecture is a convenient method for improving fuel economy in readily available conventional vehicles. This paper presents the optimization of component sizes for a through-the-road parallel HHV. The chosen combination uses a $25 \mathrm{cc} / \mathrm{rev}$ pump with a gear ratio of 2.8, a $50 \mathrm{cc} / \mathrm{rev}$ motor with a gear ratio of 1.0, and a $10 \mathrm{~L} \mathrm{HPA}$. The combination is optimal for all of the WLTP segments except for the WLTP medium. The chosen combination is acceptable, as it allows the pump and the motor to operate within their limits, and maximizes the use of regenerative braking throughout the full WLTP drive cycle.

\section{Acknowledgement}

This research was funded by RUI khas 1001/PMEKANIK/8014032 grant. 


\section{References}

[1] Tvrdić, Vjekoslav, Srdjan Podrug, Igor Šuljić, and Bernard Matić. "Hydraulic hybrid vehicle configurations and comparison with hybrid electric vehicle." In Contemporary Issues In Economy \& Technology-CIET 2018. 2018.

[2] Cobb, Jeff. "Americans buy their four-millionth hybrid car." Hybrid Cars: Auto Alternatives of the 21st Century (2016).

[3] Merritt, H. E. Hydraulic Control Systems. John Wiley \& Sons, 1967.

[4] Kepner, Ronald Paul. Hydraulic Power Assist- A Demonstration of Hydraulic Hybrid Vehicle Regenerative Braking in a Road Vehicle Application. No. 2002-01-3128. SAE Technical Paper, 2002. https://doi.org/10.4271/2002-01-3128

[5] Ramdan, Muhammad Iftishah, and Ahmad Faizul Hawary. "Perodua Myvi parallel hybrid hydraulic passenger vehicle fuel economy simulation on Malaysia drive cycle, using rule-based control strategy." In AIP Conference Proceedings, vol. 2059, no. 1, p. 020018. AIP Publishing LLC, 2019.

https://doi.org/10.1063/1.5085961

[6] DieselNet. "Worldwide Harmonized Light Vehicles Test Cycle (WLTC)." Emission Test Cycles, 2019. https://www.dieselnet.com/standards/cycles/wltp.php.

[7] Hawary, A. F. and M. I. Ramdan. "Hybrid Hydraulic Vehicle Parameter Optimization using Multi-Objective Genetic Algorithm." International Journal of Automotive and Mechanical Engineering 16, no. 3 (2019): 7007-7018. https://doi.org/10.15282/ijame.16.3.2019.13.0525

[8] Ramdan, Muhammad Iftishah, and Kim A. Stelson. "Optimal design of a power-split hybrid hydraulic bus." Proceedings of the Institution of Mechanical Engineers, Part D: Journal of Automobile Engineering 230, no. 12 (2016): 1699-1718. https://doi.org/10.1177/0954407015621817

[9] Ramdan, Muhammad Iftishah. "Perodua Myvi engine fuel consumption map and fuel economy vehicle simulation on the drive cycles based on Malaysian roads." In MATEC Web of Conferences, vol. 90, p. 01044. EDP Sciences, 2017. https://doi.org/10.1051/matecconf/20179001044

[10] Moore, Haley M., Bryan Whitney Belt, Christopher Rhoades, Ashish Vora, Haotian Wu, Peter Meckl, Vahid Motevalli, Gregory Shaver, Oleg Wasynczuk, and Haiyan Zhang. Designing a Parallel-Through-the-Road Plug-in Hybrid Electric Vehicle. No. 2012-01-1763. SAE Technical Paper, 2012. https://doi.org/10.4271/2012-01-1763

[11] Zhang, Zhongliang, Jie Chen, and Bofu Wu. "The control strategy of optimal brake energy recovery for a parallel hydraulic hybrid vehicle." Proceedings of the Institution of Mechanical Engineers, Part D: Journal of Automobile Engineering 226, no. 11 (2012): 1445-1453. https://doi.org/10.1177/0954407012445977

[12] Katrašnik, Tomaž. "Hybridization of powertrain and downsizing of IC engine-analysis and parametric study-Part 2." Energy Conversion and Management 48, no. 5 (2007): 1424-1434. https://doi.org/10.1016/i.enconman.2006.12.003

[13] Macor, Alarico, and Antonio Rossetti. "Optimization of hydro-mechanical power split transmissions." Mechanism and Machine Theory 46, no. 12 (2011): 1901-1919. https://doi.org/10.1016/i.mechmachtheory.2011.07.007

[14] Czyński, M. "Energy efficiency of hydrostatic transmission. Comparing results of laboratory and simulation tests." Scientific Problems of Machines Operation and Maintenance 43, no. 2 (2008): 59-70.

[15] Guzzella, Lino, and Antonio Sciarretta. Vehicle Propulsion Systems: Introduction to Modeling and Optimization. Springer Science \& Business Media, 2007.

[16] Yusof, Ahmad Anas, Saiful Akmal Sabaruddin, Syarizal Bakri, and Suhaimi Misha. "Simulation of System Pressure Impact on the Water Hydraulic Hybrid Driveline Performance." CFD Letters 10, no. 2 (2018): 59-75. 